\title{
PROCESSOS E REPRESENTAÇÕES EMPREENDEDORAS À LUZ DA TEORIA VISIONÁRIA DE FILION: Uma análise empírica com empreendedores em um Centro Comercial no Ceará
}

Maria Salvelina Marques Lourenço ${ }^{1}$

Antonio Jackson Alcantara Frota Antonio Jackson Alcantara Frota ${ }^{2}$

Raimundo Eduardo Silveira Fontenele ${ }^{3}$

Antonia Márcia Sousa ${ }^{4}$

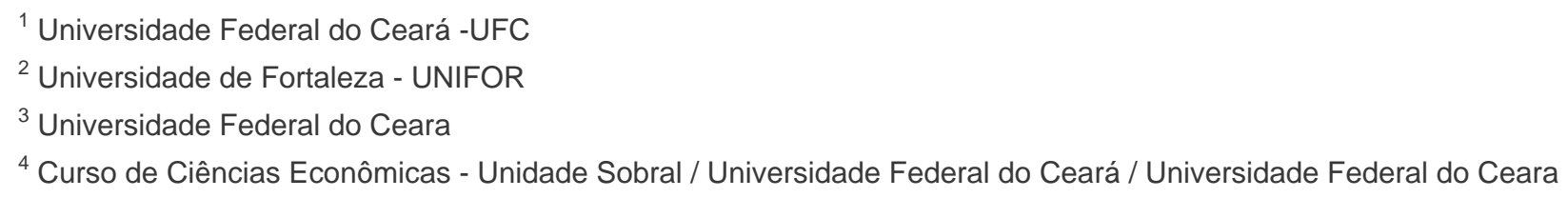

${ }^{4}$ Curso de Ciências Econômicas - Unidade Sobral / Universidade Federal do Ceará / Universidade Federal do Ceara 


\section{PROCESSOS E REPRESENTAÇÕES EMPREENDEDORAS À LUZ DA TEORIA VISIONÁRIA DE FILION: Uma análise empírica com empreendedores em um Centro Comercial no Ceará}

\section{Resumo}

Empreender é um fator de desenvolvimento socioeconômico e de realização pessoal e profissional, pode apresentar-se como oportunidade de negócio ou como alternativa para o desemprego. O objetivo dessa pesquisa é analisar o processo de criação de pequenos negócios em um centro comercial no Ceará a partir da Teoria Visionária de Filion. O design da pesquisa apresenta uma abordagem qualitativa de natureza descritiva e exploratória. A estratégia adotada é o estudo de caso. O método para coleta foi uma entrevista estruturada composta por setenta e seis questões e a observação de direta. Participaram da pesquisa onze empreendedores que atua no mercado municipal de Sobral, Ceará. Os dados foram analisados Por meio da técnica de análise de discurso. Os achados em campo mostraram que o processo de criação dos negócios não ocorreu conforme as disposições da Teoria Visionária de Filion, embora tenha sido observada uma possível influência das relações primárias na configuração da visão inicial.

Palavras-chave: Empreender, Pequenos negócios, Realização pessoal, Teoria Visionária.

\section{Introdução}

Empreendedorismo é um tema que vem despertando o interesse de governos nacionais e de organizações multinacionais, que motiva os debates nas instâncias públicas e privadas. Para Hisrich e Peters (2014), o empreendedor é indivíduo que toma iniciativa, organiza mecanismos sociais e econômicos com o propósito de apresentar algum bem decorrente dos recursos utilizados e assume riscos.

Os dados mais recentes do Global Entrepreneurship Monitor (GEM), relacionados aos comportamentos e atitudes empresariais revelam que 40,2\% da população brasileira economicamente ativa veem boas oportunidades para iniciar uma empresa na área onde vivem e $27,7 \%$ pretendem abrir um novo negócio dentro de três anos, classificando o Brasil em décimo nono entre os 65 países pesquisados (GEM, 2017).

Para Filion (2000a, p. 30), "Descobrir oportunidade de negócio é o cerne da atividade empreendedora. [...]. A oportunidade captada parece que precipita ideias em sua mente." Com o objetivo de explicar o comportamento empreendedor, Filion $(1991,1993)$ desenvolveu um metamodelo sistêmico, fruto de suas pesquisas com empreendedores bem sucedidos, assim considerados os que registraram lucratividade ou crescimento acima de determinada média, ou que "se mostraram suficientemente inovadores para serem chamados empreendedores". Para Filion (1991, p. 64), empreendedor é "alguém que concebe, desenvolve e realiza visões".

Entretanto, nem todos os negócios são criados em decorrência da percepção de uma oportunidade. Muitos são criados por falta de opções mais satisfatórias, sem que seus 
instituidores tenham os conhecimentos, as habilidades e as experiências necessárias são criadas por necessidade.

Neste contexto, em que o empreendedorismo se apresenta como uma importante alavanca do desenvolvimento socioeconômico e como instrumento de realização, compreender o comportamento empreendedor torna-se relevante, especialmente porque o empreendedorismo é um fenômeno que pode ser ensinado e estimulado e, portanto, aprendido.

Em Sobral, município situado a Noroeste do estado do Ceará, 435 pequenos negócios informais encontram-se instalados nos boxes do Mercado Central. Considerando a importância desses empreendimentos, como fonte de trabalho e renda para seus proprietários, e tendo em vista a fragilidade que, em regra, caracteriza esses pequenos negócios, este trabalho parte do seguinte problema: como ocorreu o processo de criação dos empreendimentos do Mercado Central de Sobral?Partindo dessa perspectiva, o objetivo da pesquisa é analisar o processo de criação de pequenos negócios em um centro comercial no Ceará a partir da Teoria Visionária de Filion.

$\mathrm{O}$ artigo conta com quatro seções, além desta introdução. A seção 2 trata do suporte teórico que embasa este estudo, no qual se busca o entendimento do empreendedorismo a partir da concepção dos economistas e dos comportamentalistas, com ênfase na Teoria Visionária de Filion. A seção 3 descreve os aspectos metodológicos que orientam esta pesquisa. A seção 4 apresenta os resultados e as discussões deste estudo, ressaltando os aspectos que se coadunam com a Teoria Visionária de Filion, bem como os que dela se afastam. A seção 5 sintetiza as conclusões deste estudo, mostra o alcance do seu objetivo, apresenta suas limitações e recomenda a realização de novos estudos.

\section{Empreendedor e Empreendedorismo}

A definição de empreendedor evoluiu no decorrer do tempo, à medida que a estrutura econômica mundial mudava e tornava-se mais complexa. Desde seu início, na Idade Média, quando era usada para se referir a ocupações específicas, a noção de empreendedor foi refinada e ampliada, passando a incluir conceitos relacionados com a pessoa, em vez focar apenas na ocupação. Muito mais do que aumentar a renda nacional por meio da criação de novos empregos, o empreendedorismo atua como uma força positiva no crescimento econômico ao servir como ponte entre a inovação e o mercado.

No campo teórico, as definições de empreendedorismo e empreendedor vêm apresentando uma evolução cronológica com diferentes concepções e contextos distintos, porém associados às correntes dos economistas e comportamentalistas (HISRICH et al., (2014).

Com uma argumentação conjunta, o comportamento do empreendedor é definido como alguém que identifica uma oportunidade, gera uma ideia inovadora, integrando uma combinação de recursos com a geração de lucros, sob condições de riscos financeiros e incertezas psicológicas e sociais (DEGEN, 1989; LANDSTROM et al., 2012; HISRICH et al., (2014), MOREIRA, MOREIRA E SILVA (2014); LEITE (2015), OLIVEIRA (2016), GRZYBOVSKI (2016).

Para Schumpeter (1982), a essência do empreendedorismo está na percepção e no aprimoramento das novas oportunidades no âmbito dos negócios, considerando a criação de 
uma nova forma de uso dos recursos, em que eles sejam deslocados da forma do emprego tradicional e sujeitos a novas combinações.

O empreendedor está associado a um indivíduo que toma a iniciativa de reunir os mais variados recursos com um formato diferente do tradicional, ou é capaz de reorganizar os recursos existentes e, de modo inovador, criar uma organização econômica com o propósito de obter lucro ou crescer sob condições de riscos e incertezas (GARTNER, 1992; SHAPERO,1980).

A dinâmica social e econômica contemporânea direciona o indivíduo a identificar em suas características pessoais uma intenção à ação empreendedora, seja por influência do círculo de relações, por necessidades de mudanças, pela falta de postos de trabalho ou pelo instinto nato de desenvolver o espírito empreendedor (DOLABELA, 1999).

Gibb (1995) caracteriza o empreendedor como um indivíduo que tem uma visão e um senso de identificação de oportunidades, compromete-se com ela e a conduz, pelo caminho solitário, até que consiga implementá-la de forma criativa e inovadora, conduzindo ao sucesso.

Mesmo sem um consenso absoluto sobre as diversas definições do construto empreendedorismo, observa-se que há uma uniformização de conceitos quando se discute o papel do empreendedor frente às mudanças sociais, por meio da inovação e do fomento ao desenvolvimento local com a criação de novos negócios e a geração de emprego e renda que impulsiona o desenvolvimento econômico.

\footnotetext{
Os empreendedores são pessoas diferenciadas, que possuem motivação singular, apaixonadas pelo que fazem, não se contentam em ser mais um na multidão, querem ser reconhecidas e admiradas, referenciadas e imitadas, querem deixar um legado. Uma vez que os empreendedores estão revolucionando o mundo, seu comportamento e o próprio processo empreendedor devem ser estudados e entendidos (DORNELAS, 2008, p. 19).
}

Deste modo, os empreendedores se destacam não apenas como um indivíduo apto a visualizar oportunidades de negócios que impulsionam a economia, mas como modelos de profissionais que agregam valor ao país por meio das forças direcionadoras do desenvolvimento econômico e social.

O empreendedor é um ser social, produto do meio em que vive fenômeno regional, que equilibra e destrói a ordem econômica das cidades e regiões por meio da introdução de novos produtos e serviços ou pela a exploração de novos recursos e materiais (DOLABELA, 1999; SCHUMPETER, 1934). Assim, desfaz-se a tese de que empreendedorismo é fruto de herança genética, ou seja, é possível que as pessoas aprendam a ser empreendedoras (BIRLEY; MUSYKA, 2001).

O empreendedorismo pode ser considerado também um fenômeno cultural, ou seja, é fruto de hábitos, práticas e valores das pessoas. Existem famílias mais empreendedoras do que outras, assim como cidades, regiões ou países, o que comprova a teoria de que empreendedores têm maiores chances de gerar novos empreendedores e que empreendedores de sucesso quase sempre têm um modelo, alguém a quem admiram e imitam (FILLION, 1991).

Para Kirzner (1973), o empreendedor é aquele que cria um equilíbrio, identifica uma oportunidade e dissemina uma ideia em um ambiente de caos, ou seja, o empreendedor tem a 
sensibilidade individual de perceber o novo no contexto da contradição e confusão, transformando em algo criativo a partir de muito pouco ou quase nada (BARRETO, 1998).

Shane e Venkataraman (2000) corroboram ao enfatizar que o empreendedor, como condutor de oportunidades inovadoras, deve ser capaz de determinar novas relações entre os meios e fins, identificando, assim, o potencial comercial do que está concebendo e seus possíveis impactos econômicos, sociais e ambientais.

As diferentes abordagens sobre a ação empreendedora dos construtores dessa nova economia mostram um vertiginoso crescimento na economia global, o que configura o ensino do empreendedorismo como uma possibilidade de desenvolvimento pessoal, intelectual, além de oportunizar o crescimento profissional do indivíduo por meio de uma educação empreendedora que tem sido disseminada pelas Instituições de Ensino Superior. A educação empreendedora está imbricada no comportamento empreendedor e pode ser manifesta através do estilo de vida, visão de mundo, das incertezas, da inovação, da capacidade de produzir mudanças em si mesmo e no meio ambiente.

\section{Teoria Visionária de Filion}

Para Filion (1991, p. 64) empreendedor é "alguém que concebe, desenvolve e realiza visões". O processo de desenvolvimento da visão compreende as seguintes categorias: visão emergente, visão central (interior e exterior) e visão complementar. A visão emergente ou inicial constitui-se de ideias e conceitos de produtos e/ou serviços. A visão central interior compreende o tipo de organização a ser criada para o alcance dos objetivos definidos. A visão central exterior diz respeito ao lugar a ser ocupado no mercado pelos produtos e/ou serviços. A visão complementar é constituída pelo conjunto de atividades gerenciais necessárias ao desenvolvimento e realização da ideia central. (FILION, 1993).

As três categorias de visão interagem mutuamente. "Para evoluir de uma categoria para outra, o empreendedor precisa de um alto nível de articulação pessoal, coerência e tenacidade, todos eles importantes fatores para o sucesso ou o fracasso de sua estratégia." (FILION, 1993, p. 56). O autor acrescenta que "Ao longo de sua vida, um empreendedor deve continuar a avaliar, selecionar e então integrar novas visões emergentes à sua visão central". (FILION, 1993, p. 53).

Filion (1993, p. 55) afirma que, "Quanto mais experiência o empreendedor tenha adquirido no seu campo, mais apto estará para definir claramente as visões secundárias que deseja que aconteçam." O autor ressalta a importância do conhecimento para o processo de concepção, desenvolvimento e realização da visão. Neste sentido, assevera que o empreendedor "terá que aprender a ser diferente, se desejar ocupar e manter ocupado o nicho que tiver escolhido no mercado. Terá, ainda, que adquirir conhecimento ou, mais especificamente, conhecimento relacionado com o que ele deseja realizar." (FILION, 1991, p. 64). Afirma também que "A forma de atuação do empreendedor é essencialmente proativa, já que ele identifica coisas novas que deverá aprender, tendo em vista as coisas novas que deseja realizar." (FILION, 1991, p. 64).

Com base em suas pesquisas, Filion $(1991,1993)$ desenvolveu um modelo explicativo do processo de concepção, desenvolvimento e realização da visão, um metamodelo sistêmico, que incorpora quatro elementos: weltanschauung, energia, liderança e relações. 
Figura 1 - O processo de criação da visão

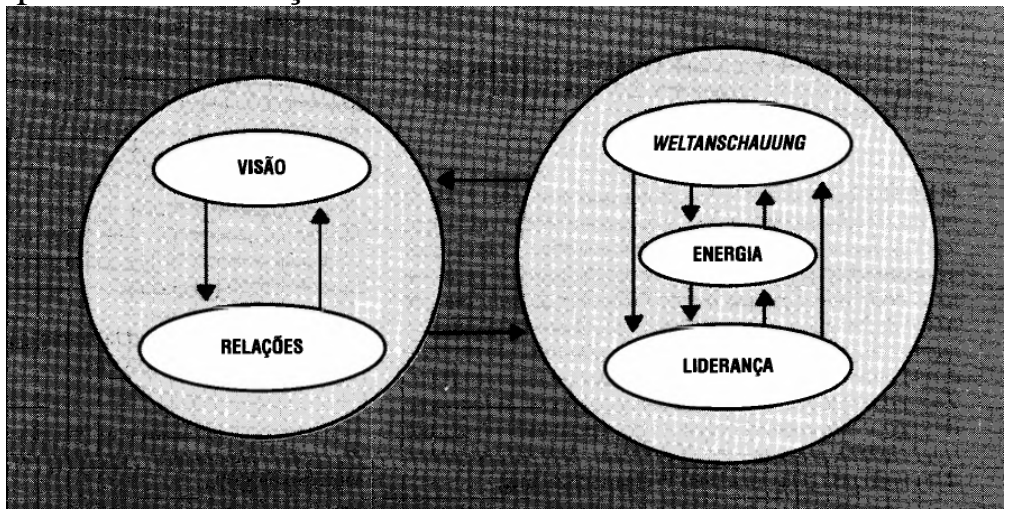

Fonte: Filion, 1991, p. 64.

A weltanschauung (W) "é o prisma através do qual o indivíduo enxerga o mundo real. (FILION, 1993, p. 56). Trata-se, portanto, da visão do mundo, ou seja, da maneira como o indivíduo percebe a realidade. Esta visão é influenciada pelas crenças, valores, atitudes, humor, intenções e percepções. Constitui o que é percebido como significativo, e está sempre associada a imagens, modelos e outras formas de representação da realidade. Assim como os valores, a weltanschauung não é definitiva; ela "evolui continuamente, reformulada à luz do contexto em que o indivíduo opera ou pretende operar". Ela constitui a base sobre a qual se desenvolve o processo de estabelecimento da visão empreendedora. (FILION, 1991, p. 65).

A energia traduz-se no tempo dedicado às atividades profissionais e também na intensidade com que essas atividades são executadas. Essa energia é influenciada pelos valores, ou seja, pelas weltanschauung (Ws). A energia despendida pode conferir mais liderança, pode levar um empreendedor a dedicar mais tempo para criar e preservar relacionamentos ou para completar uma visão, e todas essas atividades reunidas podem resultar em alterações nas suas Ws. Além disso, a energia investida para assumir a liderança deverá ser devolvida ao empreendedor, pelo menos em parte, de uma forma ou de outra, e, às vezes em quantidade maior do que ele investiu. (FILION, 1991, p. 65).

A percepção da importância da oportunidade de negócio definirá a quantidade e a intensidade da energia a ser despendida tanto, no desenvolvimento quanto na realização da visão, como também na construção e manutenção de novos relacionamentos.

A liderança é influenciada pela weltanschauung, pela energia e pelas relações, ao mesmo tempo em que influencia tais elementos. Ela afeta o desejo de realização. Sua importância para o desenvolvimento da visão decorre do seu impacto sobre o nível da visão e também da extensão do que o empreendedor pretende realizar. "A habilidade para desenvolver uma visão parece conferir liderança e esta, para o empreendedor, parece depender do desenvolvimento da visão.” (FILION, 1991, p. 65).

O sistema de relações é o principal fator de desenvolvimento e de realização da visão. (FILION, 1993, p. 52). Quanto mais articulada for a visão, mais importante será o seu papel na escolha dos critérios de estabelecimento do sistema de relações. (FILION, 1991).

O primeiro sistema de relações, o sistema básico ou das relações primárias, ocorridas geralmente no âmbito familiar, é o que mais influencia a weltanschauung, sendo, portanto, fundamental para moldar a visão inicial.

Com o passar do tempo, o empreendedor vai estabelecendo outros sistemas de relações. As relações secundárias são as desenvolvidas em torno de atividade bem definidas como 
clubes sociais, grupos religiosos, política etc. As relações terciárias, por seu turno, prestam-se a satisfazer uma necessidade bem específica, não implicando, necessariamente, contato pessoal. "A atenção dedicada ao gerenciamento dessas relações parece constituir um dos principais elementos que permitem ao empreendedor formar uma visão central coerente." (FILION, 1991, p. 69).

Filion alerta para a diferença entre administrador e empreendedor. "O empreendedor precisa identificar visões, antes que possa gerenciar recursos." (FILION, 1991, p. 71). Sobre o desenvolvimento e apresentação da visão, o autor assim se manifesta: $O$ desenvolvimento e a subseqüente apresentação de uma visão pressupõem a existência de habilidade tanto de articulação como de comunicação. Para um empreendedor explicar a sua visão, terá que saber como persuadir e, logo, terá que possuir um bom conhecimento básico dos principais elementos envolvidos. (FILION, 1991, p. 66).

Filion (1999b, p.18-19) também distingue empreendedor de operador de pequenos negócios. O empreendedor tem 'sonhos realistas' ou visões e se compromete com a realização das visões. Os operadores, por sua vez, "simplesmente querem dar bom uso às suas habilidades de forma a ganhar a vida." Os empreendedores valorizam mais as empresa que os operadores. Os empreendedores têm foco num processo de desenvolvimento, enquanto os operadores focam nas operações. Para Filion o empreendedor é também um inovador.

\section{Metodologia}

Este estudo tem como objetivo analisar o processo de criação de pequenos negócios em um centro comercial no Ceará. Para isso foi desenvolvido um estudo de caso exploratório com abordagem qualitativa. A contemplação do método qualitativo mostra representações dos atos, descrições detalhadas de situações e das expressões humanas com suas condutas e interações (Godoi, 2006; Sampieri, Collado e Lúcio, 2013). Os direcionamentos do estudo de caso foram os determinados por Yin, (2015) que define esse método como uma investigação empírica de um fenômeno contemporâneo que deve está permeada por situações de um contexto de vida real ainda não claramente definidas.

Quanto ao objetivo, esta pesquisa classifica-se como exploratória e descritiva. Exploratória porque visa "proporcionar maior familiaridade com o problema, com vistas a torná-lo mais explícito", (GIL, 2009, p. 41). Descritiva porque tem o escopo de tratar da descrição de determinado fenômeno. (GIL, 2009). O método de abordagem utilizado foi o indutivo, tendo em vista que a análise partiu de dados particulares, suficientemente constatados, para se chegar a uma generalização. (GIL, 2009).

O modelo teórico para formação da ferramenta de coleta de dados foi a Teoria Visionária de Filion. A ferramenta de coleta foi uma entrevista estruturada e a observação direta. Os dados foram coletados com 11 empreendedores, sendo 3 homens e 8 mulheres) e o critério de escolha dos entrevistados foi a acessibilidade.

O lócus da pesquisa foi o mercado central de Sobral, um dos maiores centros comerciais. O município de Sobral está situado a Noroeste do estado do Ceará. Considerando a importância desses empreendimentos como fonte de trabalho e renda para seus proprietários, e tendo em vista a fragilidade que, em regra, caracteriza esses pequenos negócios, este trabalho parte do seguinte problema: como ocorreu o processo de criação dos empreendimentos do Mercado Central de Sobral? 
Os dados foram analisados de acordo com a Análise de Discurso que, segundo Caregnato e Mutti (2006, p. 680), éuma técnica de interpretação, utilizada nas pesquisas qualitativas, que leva em consideração não apenas o aspecto literal do discurso (falado, escrito ou transcrito), mas busca alcançar o sentido da mensagem, integrando os aspectos linguísticos, sociais e históricos.

\section{Resultados e Discussão}

Este estudo foi realizado no município de Sobral, localizado no semiárido nordestino, a Noroeste do estado do Ceará, a 235 quilômetros de Fortaleza, capital do Estado. Sobral possui área territorial de $2.123 \mathrm{~km}^{2}$, e em 2010 registrava uma população de 188.233 habitantes. (IPECE, 2011). O Município tem um elevado potencial para o comércio, pois constitui um polo econômico, social e cultural da Região Norte do Ceará, atraindo muitas pessoas que buscam serviços de saúde, educação e negócios em geral.

Como alternativa de geração de ocupação e renda e buscando aproveitar o potencial econômico do município, vendedores ambulantes foram ocupando uma das praças de Sobral, a Praça da Meruoca, atualmente Praça de Cuba, onde foram instalando suas bancas de mercadoria. Em 2003, havia 403 feirantes em Sobral, os quais, depois de negociações com o Poder Executivo local, foram transferidos para o Mercado Central. Atualmente, 435 feirantes ocupam os boxes do mercado. Desses feirantes, foram entrevistados 11 (3 homens e 8 mulheres).

A análise dos dados teve como objetivo inicial identificar os motivos que levaram os entrevistados a abrir o próprio negócio: oportunidade ou necessidade. Em seguida, foi analisado o processo de concepção, desenvolvimento e realização da ideia de negócio, para saber se ocorreram as disposições da Teoria Visionária de Filion. A figura 2 mostra um panorama dos resultados.

Figura 2 - Resultados do estudo dos feirantes do Mercado Central de Sobral, em relação à Teoria Visionária de Filion.

\begin{tabular}{|l|l|l|l|l|l|l|}
\hline $\mathrm{F}$ & $\mathrm{M}$ & Visão (como surgiu a ideia do negócio) & $\mathrm{R}$ & $\mathrm{E}$ & $\mathrm{L}$ & $\mathrm{RS}$ \\
\hline 01 & 1 & $\begin{array}{l}\text { Era professora contratada do Município de Sobral foi despedida } \\
\text { do emprego. Passou a fabricar roupa e vendia nas feiras dos } \\
\text { municípios vizinhos. Soube da existência de uma vaga na Praça } \\
\text { da Meruoca. Comprou a vaga e montou a banca. }\end{array}$ & 3 & 1 & 2 \\
\hline 02 & 1 & $\begin{array}{l}\text { Foi despedida do emprego. Já tinha experiência com vendas. Foi } \\
\text { incentivada pela irmã a abrir um negócio. }\end{array}$ & $\mathrm{S}$ & 3 & 2 & 2 \\
\hline 03 & 1 & $\begin{array}{l}\text { Não encontrou emprego. Tinha desejo de montar o próprio } \\
\text { negócio. Surgiu uma vaga na Praça da Meruoca. Foi estimulada } \\
\text { por uma pessoa próxima e pelo marido. }\end{array}$ & 4 & 2 & 2 \\
\hline 05 & 1 & $\begin{array}{l}\text { Ao ser despedido do emprego, foi incentivado por um amigo a } \\
\text { montar o próprio negócio. O plano dos negócios entrega nas mãos } \\
\text { do Senhor. }\end{array}$ & $\begin{array}{l}\text { Era vendedora de uma loja e gostava do que fazia. Estava sempre } \\
\text { atenta às oportunidades de negócios. Assim, na loja em que } \\
\text { trabalhava, fazia suas vendas particulares, o que incomodava seus } \\
\text { superiores. Percebeu, então, que seria melhor montar o próprio }\end{array}$ & 3 & 2 & 2 \\
\hline
\end{tabular}




\begin{tabular}{|c|c|c|c|c|c|c|}
\hline & & negócio, pois teria mais retorno e também mais autonomia. & & & & \\
\hline 06 & 1 & $\begin{array}{l}\text { Desde } 11 \text { anos de idade que ajudava a mãe (vendedora da praça). } \\
\text { Quando ficou maior de idade foi trabalhar numa empresa e ao ser } \\
\text { despedido resolveu montar o próprio negócio. Hoje tem quatro } \\
\text { boxes e afirma: "Nunca pensei em ter quatro boxes". Atribui isto à } \\
\text { vontade do Senhor. }\end{array}$ & $S$ & 5 & 2 & 2 \\
\hline 07 & 1 & $\begin{array}{l}\text { Ao ser despedida do emprego, resolveu ser sacoleira e quando } \\
\text { surgiu uma vaga no Mercado Central, adquiriu um box e montou } \\
\text { o próprio negócio. }\end{array}$ & $S$ & 4 & 2 & 2 \\
\hline 08 & 2 & $\begin{array}{l}\text { Aos } 11 \text { anos de idade começou a ajudar o pai, no comércio. } \\
\text { Quando completou } 18 \text { anos foi trabalhar num escritório de } \\
\text { contabilidade (trabalhou em } 3 \text { escritórios, durante sete anos). Não } \\
\text { satisfeita com o salário, resolveu confeccionar enxoval para bebê. } \\
\text { Ao passar pelo Mercado Central, percebeu que ninguém ali vendia } \\
\text { enxoval de bebê, o que lhe pareceu uma boa oportunidade. } \\
\text { Comprou uma banca e as vendas foram tão elevadas que passou a } \\
\text { comprar enxoval para revender, pois sua fabricação era } \\
\text { insuficiente para atender a demanda. }\end{array}$ & $\mathrm{S}$ & 5 & $*$ & 1 \\
\hline 09 & 1 & $\begin{array}{l}\text { Ao ser despedida do emprego, passou a vender confecção em } \\
\text { casa. Quando surgiu uma vaga na Praça da Meruoca, adquiriu a } \\
\text { vaga e montou uma banca. Em relação aos planos para o futuro, } \\
\text { afirma: "A gente fica aqui só para não ficar em casa, de cara pra } \\
\text { cima." }\end{array}$ & $\mathrm{N}$ & 3 & 2 & 2 \\
\hline 10 & 1 & $\begin{array}{l}\text { "Meu marido me deixou e minhas irmãs me aconselharam a fazer } \\
\text { alguma coisa. Fui, então, procurar uma banca na praça." }\end{array}$ & $S$ & 3 & 2 & 2 \\
\hline 11 & 1 & $\begin{array}{l}\text { "Eu era garçom e minha mulher tinha essa banca. Eu imaginei que } \\
\text { ajudar a mulher ia ser mais vantajosoque ser garçom." Ao se } \\
\text { perguntar como o entrevistado caracteriza um empreendedor, } \\
\text { respondeu: "Um empreendedor tem visão comercial, de longo } \\
\text { prazo. Eu não tenho esta visão." }\end{array}$ & $\mathrm{S}$ & 3 & 2 & 2 \\
\hline
\end{tabular}

Fonte: elaboração dos autores.

Legenda:

1. $\mathrm{F}=$ Feirante.

2. $\mathrm{M}=$ Motivação (1: necessidade; 2 : oportunidade).

3. $\mathrm{R}=$ Relações - influência das relações primárias na concepção da visão ou na concretização do negócio: S: Sim; N: Não.

4. $\mathrm{E}=$ Energia - nota atribuída ao próprio desempenho (de 1 a 5) em relação ao desempenho dos demais feirantes do Mercado Central de Sobral.

5. $\mathrm{L}=$ Liderança( resposta às seguintes questões: no relacionamento com as pessoas com quem trabalha, você se percebe: 1: comandante/influente; 2: comandado/ influenciado; 3: nem influencia e nem é influenciado.

6. $\mathrm{RS}=$ Resultado acerca da ocorrência da Teoria Visionária de Filion:

1 : há fortes indícios de ocorrência; 2 : não ocorreu.

Os resultados mostram que, dos onze entrevistados, apenas as feirantes 5 e 8 apresentaram indícios de percepção de uma oportunidade de negócio, enquanto os demais entrevistados viram no empreendimento a opção para o desemprego. 
A feirante $n^{\circ} 5$ declarou que gosta muito de trabalhar com vendas, já tinha experiência de 9 anos como empregada de loja, e percebeu que ter o próprio negócio seria mais rentável e lhe daria mais autonomia. Informou que sempre está atenta às oportunidades de negócios, e deu o seguinte depoimento: "Quando eu era empregada numa loja, percebi que faltava copo para se tomar água. Resolvi, então, levar copo descartável para vender aos colegas." Filion (2000a) sublinha que, "Para uma pessoa criativa, um problema se torna uma oportunidade de negócio, pois em toda atividade humana [...] é possível descobrir certo número de problemas que a criação de novos produtos ou serviços irá resolver." Além dos copos, referida feirante vendia também outros produtos não ofertados pela loja em que trabalhava, mas que entendia serem do interesse dos clientes (bijuterias, cosméticos, perfumaria). Percebeu, então, que suas vendas particulares causavam incômodo aos seus superiores, decidindo, portanto, deixar o emprego e montar o próprio negócio.

A feirante $\mathrm{n}^{\mathrm{o}} 8$ também decidiu abrir o próprio negócio, motivada pela percepção de uma oportunidade: "ali ninguém vendia enxoval para bebê." $\mathrm{O}$ feirante $\mathrm{n}^{\circ} 11$, apesar de não ter sido dispensado do trabalho, decidiu deixar de ser garçom para ser ajudante da esposa, proprietária de um box, não manifestando indícios de percepção de oportunidade de negócios. Ressalte-se o alerta de Filion (2000a) no sentido de não se confundir ideia de negócio com oportunidade de negócio. As ideias, frequentemente, são gerais e abstratas, enquanto as oportunidades representam uma possibilidade concreta de ocupar um nicho de mercado, de atender a uma demanda não satisfeita. Neste sentido, a feirante $\mathrm{n}^{\mathrm{o}} 5$, ao decidir criar o próprio negócio, já foi pensando no tipo de produto e de cliente bem como no tipo de negócio. Fez planejamento, buscou informações e procurou um local adequado para o tipo de mercadoria. Analisou o local para ver se o ponto era bom de venda, se era claro, ventilado e próximo aos boxes de parentes. Assim, a visão emergente já foi dando corpo à visão central, interna e externa. Ao se interrogar acerca do motivo que a levou a trabalhar com esse tipo de produto (confecção masculina e feminina do tipo popular, tradicional, para adulto), declarou: "Gosto desse tipo de mercadoria e dá bom lucro. Além disso, não se deteriora, não tem prazo de validade e nem sai da moda." Sobre a evolução da ideia de negócio para a oportunidade de negócio, Filion (2000a, p. 33) assevera: É comum a descoberta de uma oportunidade de negócio surgir de uma ideia que a pessoa vai tornando mais precisa na tentativa de coloca-la dentro da realidade do mercado. Portanto, para que uma ideia seja considerada uma oportunidade de negócio e possa dar nascimento a uma empresa, ela deve representar algo diferente, produtos ou serviços novos ou um melhoramento de algo preexistente [...] corresponder a uma necessidade não satisfeita pelo mercado e, ao mesmo tempo, agregar um valor para o consumidor.

Percebe-se que o empreendedor de Filion é também um inovador, a exemplo do empreendedor de Schumpeter. É importante destacar que a feirante $n^{\circ} 5$ não colocou no mercado um produto novo. Ao se interrogar acerca de mudanças realizadas, no intuito de melhorar o atendimento e aumentar as vendas, declarou que surgiram muitas ideias de mudança (pintura dos boxes com cor diferente, organização das mercadorias), mas não foi possível realizá-las por proibição da Prefeitura, que não permite a despadronização dos boxes. Quanto aos planos futuros, afirmou que brevemente inaugurará um novo box com confecção infantil. Assim, novas ideias emergentes surgem, podendo-se associar à ideia central. Entretanto, o novo box não configura uma inovação, pois comercializará produtos tradicionais. 
A feirante $\mathrm{n}^{\circ} 8$ levou para o Mercado Central um produto até então inexistente no local: enxoval de bebê. Ao se perguntar sobre mudanças para melhorar o atendimento e aumentar as vendas, informou que se preocupa muito com a apresentação da mercadoria e sempre procura uma maneira diferente para expor os produtos. "Se a mercadoria já está bem apresentada, a gente não perde tempo mostrando; o cliente vê. A gente só precisa negociar o preço. Tem um detalhe: é preciso mudar sempre a posição da mercadoria. Se o cliente vê sempre a mesma mercadoria no mesmo local, a vista dele cansa. Às vezes basta mudar o local para dar a impressão de que se trata de uma nova mercadoria". (FEIRANTE $\mathrm{N}^{\circ} 8$ )

De fato, a referida feirante tem apenas dois boxes, mas consegue dar bem mais visibilidade aos seus produtos que um dos feirantes, proprietário de quatro boxes. Enquanto ela distribui a mercadoria na frente da loja, no sentido horizontal e vertical, formando um grande painel, ele empilha as peças dentro dos boxes. Ainda com relação a mudanças, a feirante $\mathrm{n}^{\circ} 8$ declarou também que "Quando eu vejo alguma coisa que eu acho interessante, eu não faço igual, mas aproveito a ideia e modifico."

Em relação à aprendizagem, os entrevistados declararam que não participam de seminários, feiras, palestras ou similares, e tudo o que aprenderam foi com a prática. Dos onze entrevistados, oito já tinham experiência com vendas, antes de abrir o próprio negócio. A feirante $n^{0} 5$ declarou que, como já tinha experiência de 9 anos como vendedora de loja, começou o próprio negócio com alguma "bagagem". Entretanto, precisou aprender a trabalhar com o "povão". "Na loja em que eu trabalhava, as pessoas podiam fazer seus pagamentos com cartão de crédito; aqui as pessoas pagam com dinheiro e isto dificulta as vendas. É preciso também saber se as pessoas preferem preço baixo ou qualidade da mercadoria." A feirante $\mathrm{n}^{\circ}$ 8 afirmou que seus 12 anos de experiência no comércio e 7 anos de experiência em escritórios de contabilidade foram fundamentais para o desenvolvimento do negócio.

A análise dos elementos que dão suporte ao desenvolvimento e realização da visão revela os seguintes resultados:

Relações - dos onze entrevistados, apenas a feirante $n^{\circ} 9$ declarou que não tem nenhum parente que seja proprietário de um negócio próprio, que não conhece nenhum empresário que lhe desperte admiração e que não foi incentivada por ninguém. Os demais, além de terem parentes ou pessoas próximas (amigos) que sejam empresários, alguns foram por eles incentivados ou neles se inspiraram. A feirante $\mathrm{n}^{\mathrm{o}} 8$ afirma que foi inspirada pelo pai e tem cinco irmãos empresários. $\mathrm{O}$ feirante $\mathrm{n}^{\mathrm{o}} 11$ fala com entusiasmo do exemplo de dois primos: "Um deles começou vendendo farinha branca no mercado. Hoje está muito bem de vida. O outro começou vendendo relógio na rua. Hoje ele tem oito lojas." Filion (1993) ressalta a influência das relações primárias, especialmente na configuração da visão inicial.

O desenvolvimento e a realização da visão também encontram no sistema de relações o seu principal fator. (FILION, 1993, p. 52). Neste sentido, é importante destacar o relacionamento da feirante $\mathrm{n}^{\circ} 5$ com os clientes e com os colaboradores. Com o intuito de se distinguir dos concorrentes, a referida feirante afirmou que sempre telefona para os clientes, comunicando a chegada de mercadoria nova, e propõe enviar a referida mercadoria para a residência do cliente, "para ele dar uma olhada sem compromisso." Em relação aos colaboradores, preocupa-se com o treinamento constante e sempre procura meios de mantêlos motivados. A feirante $\mathrm{n}^{\circ} \mathbf{9}$, por seu turno, pensa diferente. Ao se perguntar o que ela faz para conquistar os clientes e aumentar as vendas, responde: "Lidar com gente é muito difícil; tem cliente que a gente tem vontade de...". Em relação ao relacionamento com os demais 
feirantes, declarou que "às vezes a gente tem que engolir muita coisa." A feirante $\mathrm{n}^{\mathrm{o}} 1$ considera os demais feirantes "egoístas e invejosos".

A energia é definida como o tempo dedicado às atividades profissionais, bem como a intensidade com que essas atividades são realizadas. Ela é influenciada pelos valores (weltanschauung) do empreendedor. (FILION, 1991, 1993). Assim, quanto mais importante for o negócio para o empreendedor, mais energia ele estará disposto a investir nas suas atividades empresariais. Os feirantes entrevistados declararam que dedicam de 5 a 12 horas por dia às atividades empresariais. Ao ser solicitada a atribuição de uma nota, de 1 a 5, para o desempenho de cada entrevistado, em relação ao desempenho dos demais feirantes, foram obtidas as seguintes respostas: $55 \%$ atribuíram-se a nota 3, 18\% atribuíram-se a nota 4 e $27 \%$ atribuíram-se a nota 5. Digna de destaque negativo é a afirmação da feirante $n^{\circ} 9$, que dedica 5 horas diárias ao negócio e declara que "A gente fica aqui só pra não ficar em casa, de cara pra cima." Segundo Filion (1999b, p. 18), "Empreendedores têm 'sonhos realistas', ou visões, com cuja realização está comprometida."

A liderança também foi avaliada a partir da auto percepção de cada feirante. Assim, ao se perguntar se o entrevistado se percebe comandante/influenciador (líder) ou comandado/influenciado (liderado), apenas dois se declararam líderes (as feirantes 1 e 5). A feirante $\mathrm{n}^{\circ} 8$ revelou que nem influencia e "nem vai pela cabeça dos outros." Filion (1991 p. $65 ; 1993$, p. 58) afirma que "A habilidade para desenvolver uma visão parece conferir liderança, e esta, para o empreendedor, depende do desenvolvimento da visão."

\section{Considerações Finais}

O objetivo deste trabalho foi verificar se ocorreu o processo visionário de Filion com os feirantes do Mercado Central de Sobral, cujos negócios foram motivados pela necessidade de trabalho e renda para seus criadores.Os resultados apresentados permitem concluir que, dos onze entrevistados, apenas dois criaram o próprio negócio motivados pela percepção de uma oportunidade (as feirantes 5 e 8), sendo os demais motivados pela necessidade. Nos feirantes motivados pela percepção de uma oportunidade há fortes indícios de ocorrência das disposições da Teoria Visionária de Filion, especialmente em relação à feirante $n^{\circ} 5$.

No caso dos feirantes motivados pela necessidade, a ideia de negócio surgiu e logo foi implementada, de maneira apressada, sem o devido planejamento, sem a busca de informações, sem o conhecimento necessário, contrariando os preceitos da Teoria Visionária de Filion. Os produtos ofertados são tradicionais e as mudanças efetuadas não configuram a inovação que caracteriza o empreendedor de Filion, que "identifica coisas novas que deverá aprender, tendo em vista as coisas novas que deseja realizar." (FILION, 1991. p. 64). É importante destacar que a dificuldade de inovação parece ser uma característica dos empreendimentos do Brasil. De acordo com a pesquisa do GEM (2011, p. 64), mais de 92\% dos empreendedores brasileiros estabelecidos (que contam com mais de 42 meses de criação), afirmam que "ninguém considera seus produtos novos."

Os resultados mostram também que, nos feirantes motivados por necessidade, não há evidências de ocorrência da visão central, ou seja, da imagem projetada no futuro do tipo de produto ou serviço a ser oferecido e do tipo de organização necessária ao atendimento do objetivo, o que demandaria, pelo menos, um mínimo de planejamento de médio e longo prazo. "Os empreendedores não apenas definem situações, mas também imaginam visões sobre o que desejam alcançar." (FILION, 2000b, p. 6). Não foram constatadas atitudes de 
liderança, e a energia dependida no negócio poderia ser intensificada. O sistema de relações limita-se a comprar e revender.

Assim, é possível afirmar que não ocorreu o disposto na Teoria Visionária de Filion entre os nove feirantes motivados por necessidade. Entretanto, 67\% desses feirantes declararam haver na família pessoas que têm um negócio próprio, o que pode ter influenciado a visão inicial, conforme assevera Filion (1991, p. 63): "O sistema básico de relações de um empreendedor, a família, com certeza moldará os tipos de visão inicial que ele possa ter."

Um traço marcante observado nesses feirantes é que eles não falam do empreendimento com o mesmo entusiasmo observado nos feirantes motivados pela oportunidade. Entretanto, todos consideram que o seu ramo de atividade é um bom negócio e todos se declararam satisfeitos com o empreendimento.

Fato curioso é a longevidade desses pequenos negócios, cujo tempo de existência varia de doze a vinte anos, contrariando as pesquisas que atestam a morte precoce dos empreendimentos criados sem o planejamento adequado, geralmente informais e motivados por necessidade. Segundo Dornelas (2005, p. 28), "esses negócios [...] fracassam bastante rápido, não gerando desenvolvimento econômico e agravando as estatísticas de criação e mortalidade dos negócios."

Tendo em vista que a morte precoce de micro e pequenos negócios constitui uma triste realidade da economia brasileira, e considerando a importância da sobrevivência desses empreendimentos para a geração de trabalho e renda, seria recomendável um estudo no sentido de averiguar as causas da longevidade dos empreendimentos do Mercado Central de Sobral.

É importante destacar que este trabalho apresenta algumas limitações: a) seus resultados não podem se generalizados para a população; b) a análise do processo visionário é bastante complexa, especialmente por envolver subjetividades, o que demandou constantes idas e vindas aos dados e à teoria, como forma de assegurar a compreensão do sentido e do alcance das declarações.

Entretanto, considera-se que o objetivo deste trabalho foi alcançado, tendo em vista que foi possível verificar se ocorreu o processo visionário de Filion com os feirantes do Mercado Central de Sobral, motivados pela necessidade de trabalho e renda.A análise dos dados permitiu concluir que o processo de criação desses negócios não ocorreu conforme as disposições da Teoria Visionária de Filion, embora tenha sido observada uma possível influência das relações primárias na configuração da visão inicial.

\section{Referências}

BARRETO, L. P. Educação para o Empreendedorismo. Salvador: Escola de Administração de Empresas da Universidade Católica de Salvador, 1998.

BOAVA, D. L. T.; MACEDO, F. M. F. Estudo sobre a essência do empreendedorismo. In: EnANPAD, 30., 2006, Salvador. Anais... Salvador, 2006.

BRAGA, J. N. de P. O empreendedorismo como instrumento de desenvolvimento: o programa IES-SOFTEX. 2003. 123 f. Dissertação (Mestrado Profissional em Administração) - Escola de Administração, Universidade Federal da Bahia, Salvador, 2003. 
BIRLEY, S., MUZIKA, D. Dominando os desafios do empreendedor. São Paulo: Makron Books, 2001.

CAMARGO, D. de; CUNHA, S. K. da; BULGACOV, Y. L. M. A psicologia de McClelland e a Economia de Schumpeter no campo do empreendedorismo. RDE, Salvador, a. 10, n. 17, p. 111-120, jan. 2008.

CAMPOMAR, M.C. Do uso de "estudo de caso" em pesquisas para dissertações e teses em administração. Revista de Administração, São Paulo, v. 26, n. 3, p. 95-97, jul./set. 1991.

CAREGNATO, R.C.A.; MUTTI, R. Pesquisa qualitativa: análise de discurso versus análise de conteúdo. Texto Contexto, Florianópolis, v. 15,n. 4, p. 679-684, out./dez. 2006.

DEGEN, R. J. Empreendedor: fundamentos da iniciativa empresarial. São Paulo: MacGrawHill, 1989.

DORNELAS, J. C. A. Empreendedorismo: transformando ideias em negócios. 2. ed. Rio de janeiro: Elsevier, 2005.

DOLABELA, F. Segredo de Luiza. São Paulo: Cultura, 1999.

GEM-Global Entrepreneurship Monitor, 2017. Disponível em:

<http://www.sebrae.com.br/atender/customizado/estudos-e-pesquisas>. Acesso em: 20 out. 2017

GIBB, A. A. Entrepreneurship and small business management: can we afford to neglect them in the twenty-first century business school? British Journal of Management, Vol. 7, No.4, pp.309-21, 1995.

GODOI, Christiane Kleinübing; BANDEIRA-DE-MELLO, Rodrigo; SILVA, Anielson. "Pesquisa qualitativa e o debate sobre a propriedade de pesquisar" in: GODOI, Christiane Kleinübing et al. Pesquisa qualitativa em estudos organizacionais - paradigmas, estratégias e métodos. São Paulo: Saraiva, 2006, p.1-16.

HISRICH, R. D. Empreendedorismo. 9a Ed. Porto Alegre: Bookman, 2014.

GRZYBOVSKI, D. Empreendedorismo e gestão de pequenas empresas: uma contribuição do egepe 2016. Gestão \& PlanejamentoG\&P, 17(2), 2016.

KIRZNER, I. M. Competition and Entrepreneurship. Chicago, IL: University of Chicago Press, 1973.

FILION, L. J. O planejamento do seu sistema de aprendizagem empresarial: identifique uma visão e avalie o seu sistema de relações. RAE, São Paulo, v. 31, n.3, p. 63-71, jul./set. 1991.

Visão e relações: elementos para um metamodelo empreendedor. RAE, São Paulo, v. 33, n. 6, p. 50-61, nov./dez 1993. 
J. Empreendedorismo: empreendedores e proprietários-gerentes de

pequenos negócios. Revista de Administração, São Paulo, v. 34, n. 2, p. 5-28, abril/junho, 1999a.

Diferenças entre sistemas gerenciais de empreendedores e

operadores de pequenos negócios. RAE, São Paulo, v. 39,n. 4, p. 6-20, out/dez 1999b.

Oportunidades de negócios. In: FILION, L. J.; DOLABELA, F. Boa Idéia! E agora? São Paulo: CulturaEditoresAssociados, 2000a.p. 30-41.

Empreendedorismo e Gerenciamento: processos distintos, porém complementares. RAE Light, v. 7, n. 3, p. 2-7, jul./set. 2000b.

GARTNER, W. B.; BIRD, B. J.; STARR, J. A. Acting as if: Differentiating entrepreneurial from organizational behavior. Entrepreneurship Theory and Practice, v. 16, n. 3, p. 13-32, 1992.

GIL, A. C.Como elaborar projeto de pesquisa. 4. ed. São Paulo: Atlas, 2009.

IPECE. Perfil Básico Municipal: Sobral, Fortaleza, 2011. Disponível em:

<http://www.ipece.ce.gov.br/publicacoes/perfil_basico/pbm-2011/Sobral.pdf. >Acesso em: 18 jun. 2012.

LANDSTRÖM, H. Pioneers in Entrepreneurship research.Disponível

em:<http://link.springer.com/content/pdf/10.1007/0-387-25987-2_2\#page-1>. Acesso em: 05 fev. 2019.

LANDSTRÖM, H.; HARIRCHI, G.; ÅSTRÖM, F. 2012. Entrepreneurship: Exploring the knowledge base. Research Policy, 41(7), p.1154-1181, 1994.

LEITE, E.F. Empreendedorismo, Inovação, Incubação de Empresas e Startups. Recife: Bagaço, p.551, 2015

MOREIRA, H. S. A.; MOREIRA, M. A.; SILVA, W. A. C. Dez anos de pesquisa em empreendedorismo apresentados nos Enanpad de 2003 a 2012: análise dos autores engajados na área. Revista de Empreendedorismo e Gestão de Pequenas Empresas, v. 3, n. 1, p. 33-55, 2014.

OLIVEIRA, E.M. Empreendedorismo social no Brasil: atual configuração, perspectivas e desafios-notas introdutórias. Revista da FAE, 7(2), 2016. OSWALD, R. Empreendedorismo: uma revisão bibliométrica sobre o perfil empreendedor na base de dados spell. Revista Conexão, (4), p.1- 19, 2017.

SAMPIERI, R. H.; COLLADO, C. F.; LUCIO, M. P. B. Metodologia de pesquisa. 5 ed. Porto Alegre: Penso, 2013. 
SHAPERO, A.; SOKOL, L. The Social dimensions of entrepreneurship. In: Encyclopedia of Entrepreneurship. Englewood Cliffs, NJ: Prentice-Hall Inc., 1982.

SHANE, S.; VENKATARAMAN, S. The promise of entrepreneurship as field of research. Academy of Management Review, 25: 217-226. 2000.

SCHUMPETER, J. A. A A teoria do desenvolvimento econômico. São Paulo: Abril Cultural, 1982.

SEBRAE. Global Entepreneurship Monitor: Empreendedorismo no Brasil. Relatório Executivo - 2004. Curitiba: SEBRAE, 2005.

YIN. R. K. Estudo de caso:planejamento e métodos. Porto Alegre: Bookman, 2015 